\title{
Patient satisfaction as a psychological dimension after rhinoplasty: A randomized study
}

\author{
Redžo Čauševićc * , Irmelina Karić², Sanela Salihagićs ${ }^{3}$ Indira Prguda4, Dženana Hrustemovićs,6
}

${ }^{1}$ Faculty of Health Studies, University of Sarajevo, Sarajevo, Bosnia and Herzegovina, ${ }^{2}$ CEPS High School of Business Studies Kiseljak, Kiseljak, Bosnia and Herzegovina, ${ }^{3}$ Clinic of Reconstructive and Plastic Surgery, Clinical Centre of University of Sarajevo, Sarajevo, Bosnia and Herzegovina, "Faculty of Teacher Education "Džemal Bijedić" University, Mostar, Bosnia and Herzegovina, ${ }^{5}$ Discipline for Science and Teaching, Organizational Unit for Quality and Safety of Health Services, Clinical Center of Sarajevo University, Sarajevo, Bosnia and Herzegovina, ${ }^{6}$ Faculty of Pharmacy and Health, University of Travnik, Travnik, Bosnia and Herzegovina

\begin{abstract}
Introduction: Rhinoplasty is an esthetic and functional nasal reconstruction surgery. The elimination of physical disabilities directly affects mental health and leads to a better psychological balance. Therefore, patient satisfaction is considered a valuable measure of medical service outcomes. The objectives of this study were to evaluate subjective patient satisfaction 1 year after surgery and its influence on the quality of life.
\end{abstract}

Methods: This was a clinical, retrospective, randomized, and single-blinded study in which patients were randomly questioned by the same examiner. All subjects underwent pre-operative preparation and post-operative flow at Eurofarm Centre from 2007 to 2010. The survey was conducted through anonymous questionnaires that were provided to each respondent at least 1 year after discharge from the hospital.

Results: Overall, 20 (50\%) patients had esthetic and 20 (50\%) had functional nasal surgery. Most respondents were born between 1971 and 1980 (52.5\%) and between 1981 and 1991 (40\%), with the least born between 1951 and 1960 (2.5\%). Regarding the education level, 27 had university degrees (67.5\%), 1 had postgraduate education (2.5\%), and 12 (30.0\%) were secondary school graduates. In addition, 25 $(62.5 \%)$ were unmarried and 15 (37.5\%) were married.

Conclusion: No statistically significant correlation was found between the subjective assessment of patient's health based on eight dimensions of health assessment and variables such as type of surgery, age, level of education, and marital status 1 year after undergoing rhinoplasty. A statistically significant difference was found between the type of surgery and physical pain $(p=0.004<0.05$, Mann-Whitney $U$ test). Based on the research findings, we can conclude that patient satisfaction after undergoing rhinoplasty was moderately correlated positively with the quality of life $(r=0.180-0.345, p<0.05)$.

Keywords: Nursing care; patient satisfaction; rhinoplasty; quality of life

*Corresponding author: Redžo Čaušević, Faculty of Health Studies, University of Sarajevo, Sarajevo, Bosnia and Herzegovina. E-mail: redzo.causevic@fzs.unsa.ba

Submitted: 14 April 2020/Accepted: 26 November 2020

DOI: https://doi.org/10.17532/jhsci.2020.930

\section{INTRODUCTION}

Cosmetic surgery is defined as surgery of the possible - a definition that reflects an awareness of both limited reach and unheard-of possibilities. In recent years, cosmetic plastic surgery has experienced 
immense development and success because of advancements in medical science and technology and a growing number of good and experienced surgeons. In the United States alone, approximately 1.5 million people undergo cosmetic surgery annually, which is 10 times more than that a few years ago (1).

Nevertheless, for healthy people, physical health is often insufficient. Looking in the mirror from a different perspective can result in mental stress. The foundation for a personal sense of well-being cannot be achieved without satisfaction with oneself or even with one's physical appearance. Performing cosmetic surgery after reconstructive surgery involves challenges that the art of body shaping provides, and science-based contributions to the art of beauty surgery have a growing role in contemporary medical literature. With the development of society and the expansion of world views regarding the position of cosmetic surgery in society, body reconstructions have become a characteristic of almost every human being. People undergo esthetic surgery for greater inner satisfaction and because it is a painless technique to achieve social affirmation related to existence (2). The appearance and beauty of the face depend on the look and beauty of its parts. Notably, the nose occupies a central position in the face and significantly influences the overall facial appearance, which is why esthetic nose surgery is one of the most common cosmetic procedures as well as the oldest. These surgeries are often not only esthetic in nature but are also performed to functionally resolve the difficult passage of air through the nose, in the case of a deviated nasal septum. Rhinoplasty is a procedure performed to change the shape and size of the nose to improve the overall appearance of a person's face. The most common indications for rhinoplasty are inappropriate size or shape and deformity of the nose acquired by birth, trauma, or previous surgery. Also, deviated nasal septum is associated with breathing difficulty. From an esthetic perspective, each face has a different nose shape, which is why cosmetic surgery is often individualized. Hence, considering the individual features, rhinoplasty achieves a new shape and position of the nose, restoring it as the central and most striking facial part (3). According to the American Society for Plastic Surgery, rhinoplasty is the second most popular cosmetic surgery. Moreover, rhinoplasty enjoys a high level of success in America, with more than 100,000 Americans undergoing rhinoplasty each year. Furthermore, according to the American Society of Plastic Surgeons, over the past 2 years, nearly 600,000 people have undergone rhinoplasty in the United States. People who have undergone rhinoplasty typically express their satisfaction through the facial balance they achieve after surgery. Rhinoplasty is not only a process of correcting or perfecting a physical condition but is also crucial in restoring patient confidence, providing functional assistance, and achieving a better quality of life. After rhinoplasty, the patient can often return to performing normal activities. Rhinoplasty is a procedure that, with proper care, will not interfere with the patient's quality of life, and for which there are indicators in a short time after surgery (4). Plastic surgery has developed into a mass phenomenon and the subject of analysis of several experts, most notably medics, psychologists, sociologists, and anthropologists, who view it from various aspects, interpreting whether it is a necessity or a whim of the modern age. Unless it involves the repair of a congenital or acquired anomaly, the question arises as to what prompts an individual to undergo an operation on the part of the body that is often painful, with the ever-present risk of unwanted complications. The answer to this probably has a psychological dimension based on an individual conforming to the social and popular standards of beauty and repairing the self-esteem by achieving the generally accepted desirable appearance. Plastic surgery is not a universal cure for all real difficulties, although in certain cases, it can enhance the satisfaction of social interaction and help remove barriers to further emotional development. The outer nose is a feature of utmost significance in defining the overall appearance of the face because the face reflects a person's interior to the outside world. Any change in the appearance of the nose is expected to have significant consequences in psychological and social functioning. Indeed, this is evidence that in esthetic surgery, rhinoplasty is certainly a type of surgery that has the greatest potential for altering an individual's life, especially because psychosocial dynamics can develop the ability to change a person's view as well as the views of others (5). Valuing the physical body has a considerable influence on the mental health of 
individuals. Humans have physical, psychological, and social needs, and with the fulfilment of these needs, the body's internal equilibrium is established. Any alteration of this balance will lead to problems. Psychological stress after treatment can cause emotional distress in the patient, such as anger, depression, and hopelessness (6). Assessment of the quality of life is crucial when analyzing the results of cosmetic surgery because patient satisfaction is the dominant factor that defines its success. Over the past 10 years, such measurements have greatly contributed to improving health interventions and services. Nevertheless, the generic quality of life assessment tools has certain limitations in detecting the causes of satisfaction or dissatisfaction in healthy individuals (7). Goals of this research are to determine the degree of subjective satisfaction of the respondents 1 year after undergoing rhinoplasty, to analyze the difference in the subjective assessment of post-operative health among the respondents who underwent rhinoplasty for esthetic and functional reasons, to determine whether the age, level of education and marital status of the respondents were, correlated with physical and mental health, and to correlate post rhinoplasty satisfaction with the respondents' quality of life.

\section{METHODS}

This was a clinical, retrospective, randomized, and single-blinded study in which patients were randomly questioned by the same examiner. All subjects underwent pre-operative preparation and post-operative flow at Eurofarm Centre from 2007 to 2010. Data regarding patients and their surgical courses were obtained from medical records. The survey was conducted through anonymous questionnaires that were provided to each respondent at least 1 year after discharge from the hospital. To evaluate the degree of subjective satisfaction 1 year after undergoing rhinoplasty and its effect on the quality of life as well as the effects of age, education, and marital status of the respondents on the degree of postoperative satisfaction, a purposeful questionnaire was designed per the goals and hypotheses of our work. The data were analyzed at the Eurofarm Clinic separately for esthetic and functional nose surgery to evaluate the reasons that influenced the respondents' decision regarding the type of procedure. All data were statistically analyzed using SPSS version 17.0.

\section{RESULTS}

The study respondents were women $(N=40)$ who underwent reconstructive and esthetic surgery from 2007 to 2010 at the Eurofarm Centre, Polyclinic Ilidza, Sarajevo, as follows:

- 20 respondents underwent functional nose surgery.

- 20 respondents underwent cosmetic nose surgery.

Regarding the respondents' age, most of them (21, $52.50 \%$ ) were born during the period 1971-1980, slightly fewer respondents $(16,40 \%)$ were born during the period 1981-1991. On the other hand, only two respondents (5\%) were born between 1961 and 1970, whereas only one patient (2.5\%) was born between 1950 and 1960. The health assessment scale included the following dimensions: Health rating, getting sick, comparing health with others, worsening health, and satisfaction with health, which has been presented in Table 1 . The reliability of this scale was statistically acceptable (Cronbach's alpha $=0.646$ ). It should be noted that a variable related to comparing health with others was omitted from the subscale to satisfy the criterion of internal consistency or homogeneity of the subscale (Cronbach's alpha > 0.600).

In accordance with the previously established research method, the type of surgery and the health status of the respondents (Table 2), eight new variables were included (physical functioning, limitation

TABLE 1. Perception of the general health status of the respondents 1 year after undergoing the reconstructiveesthetic procedure

\begin{tabular}{lc}
\hline Perception of general health & $\begin{array}{c}\text { Cronbach's alpha } \\
\text { reliability indicator }\end{array}$ \\
\hline Compared with your pre-operative & 0.315 \\
condition, how would you evaluate your & \\
health 1 year after undergoing surgery? & \\
I am as healthy as anyone I know & 0.586 \\
I think my health will worsen & 0.644 \\
My health is excellent & 0.634 \\
Overall reliability indicator & 0.646 \\
\hline
\end{tabular}


TABLE 2. Type of surgery and health status of respondents (Mann-Whitney $U$ test)

\begin{tabular}{lccrc}
\hline Scale & $\begin{array}{c}\text { Assessing the health of the } \\
\text { respondents (FO) }\end{array}$ & $\begin{array}{c}\text { Assessing the health of } \\
\text { the respondents (EO) }\end{array}$ & "Mann-Whitney U" & $p$ \\
\hline Physical functioning & 21.63 & 19.38 & 177.50 & 0.541 \\
Restriction owing to physical disabilities & 20.95 & 20.05 & 191.00 & 0.594 \\
Body aches & 25.20 & 15.80 & 106.00 & 0.004 \\
Perception of general health & 18.65 & 22.35 & 163.00 & 0.303 \\
Vitality and energy & 17.70 & 23.30 & 144.00 & 0.121 \\
Social functioning & 20.78 & 20.23 & 194.50 & 0.874 \\
Restriction owing to emotional distress & 20.50 & 20.50 & 200.00 & 1.000 \\
Mental health & 23.80 & 17.20 & 134.00 & 0.069 \\
\hline
\end{tabular}

owing to physical difficulties, physical pain and perception of general health, vitality and energy, social functioning, limitation owing to emotional difficulties, and mental health) as the average of the mentioned variables of each of the respondents. This method was used to analyze the differences among respondents to accept or reject any difference in attitudes regarding subjective health assessment, as well as among respondents who underwent rhinoplasty for functional reasons and those who underwent rhinoplasty for esthetic reasons. Similar results were observed between respondents who underwent rhinoplasty for functional reasons and those who underwent rhinoplasty for esthetic reasons based on physical and mental health $(p=0.343>0.05$; $p=0.946>0.05$, Mann-Whitney U test).

There was no statistically significant difference $(p>0.05)$ among the respondents. Nevertheless, a statistically significant difference $(p=0.004<0.05$, Mann-Whitney $U$ test) was observed among the respondents only regarding physical pain. These results indicate that the type of surgery affected the patients' physical pain in functional rhinoplasty.

One-way analysis of variance (ANOVA) was performed to accept or reject a possible difference in attitudes regarding subjective health assessment among respondents with varying ages (Table 3).

No statistically significant difference $(p>0.05)$ was found among the respondents with varying ages based on all eight dimensions of the health assessment. Analysis of the results confirmed that the subjective assessment of health was not affected by patients' age. Similar results were observed upon testing differences based on physical and mental health among respondents with varying ages.
In both cases, a statistically non-significant value $(p=0.573>0.05 ; p=0.213>0.05$, one-way ANOVA) was recorded.

It can be observed from Table 4 that was is no statistically significant difference $(p>0.05)$ among the respondents with different educational levels based on all eight dimensions of health assessment.

The results revealed that the level of education did not influence the subjective assessment of the respondents' health. Notably, similar results were observed upon testing differences among respondents with different educational levels based on physical and mental health, with a statistically insignificant value $(p=0.625>0.05 ; p=0.085>0.05$, one-way ANOVA).

The results indicate that there was no significant difference $(p>0.05)$ between married and unmarried respondents, based on all eight dimensions of health assessment (Table 5.)

The obtained results, presented in Table 5, confirmed that the marital status did not affect the subjective assessment of the respondents' health. Similar results were observed upon evaluating differences between the two sub-samples based on physical and mental health. In both cases, a statistically non-significant value $(p=0.341>0.05 ; p=0.167$ $>0.05$ Mann-Whitney U test) was recorded.

Table 6 shows that the respondents' satisfaction and quality of life were moderately positively correlated $(r=0.180-0.345, p<0.05)$.

A similar observation was made regarding the respondents' satisfaction related to physical and mental health $(r=0.225-0.250, p<0.05)$. Based on the values $(r=0.180-0.345, p<0.05$; Pearson correlation) 
TABLE 3. Age and health of respondents (one-way analysis of variance [ANOVA])

\begin{tabular}{|c|c|c|c|c|c|c|}
\hline Scale & $\begin{array}{c}\text { Assessing the health } \\
\text { of the respondents } \\
\text { born in the period } \\
1951-1960\end{array}$ & $\begin{array}{l}\text { Assessing the } \\
\text { health of the } \\
\text { respondents born } \\
\text { in 1961-1970 }\end{array}$ & $\begin{array}{c}\text { Assessing the health } \\
\text { of the respondents } \\
\text { born in the period } \\
1971-1980\end{array}$ & $\begin{array}{c}\text { Assessing the health } \\
\text { of the respondents } \\
\text { born in the period } \\
1981-1991\end{array}$ & $\begin{array}{c}\text { One-Way } \\
\text { ANOVA (F) }\end{array}$ & $p$ \\
\hline Physical functioning & 1.00 & 1.86 & 2.19 & 2.20 & 1.639 & 0.197 \\
\hline Body aches & 2.00 & 1.12 & 1.16 & 1.46 & 1.659 & 0.193 \\
\hline $\begin{array}{l}\text { Restriction owing to } \\
\text { physical disabilities }\end{array}$ & 2.00 & 1.87 & 1.97 & 1.92 & 2.568 & 0.070 \\
\hline $\begin{array}{l}\text { Restriction owing to } \\
\text { emotional distress }\end{array}$ & 1.66 & 1.75 & 1.90 & 1.90 & 1.715 & 0.181 \\
\hline Vitality and energy & 3.00 & 3.56 & 3.53 & 3.57 & 0.223 & 0.880 \\
\hline Mental health & 2.33 & 1.22 & 1.87 & 2.00 & 0.753 & 0.528 \\
\hline Social functioning & 1.50 & 1.00 & 1.61 & 1.46 & 1.295 & 0.291 \\
\hline $\begin{array}{l}\text { Perception of } \\
\text { general health }\end{array}$ & 3.50 & 3.62 & 3.61 & 3.58 & 1.633 & 0.199 \\
\hline
\end{tabular}

TABLE 4. Education level and health of respondents (one-way ANOVA)

\begin{tabular}{|c|c|c|c|c|c|}
\hline Scale & $\begin{array}{l}\text { Assessing the health } \\
\text { of the respondents } \\
\text { SSS }\end{array}$ & $\begin{array}{l}\text { Assessing the health } \\
\text { of the respondents with } \\
\text { VSS }\end{array}$ & $\begin{array}{l}\text { Assessing the health } \\
\text { of the respondents with } \\
\text { PDS }\end{array}$ & One-way ANOVA & $p$ \\
\hline Physical functioning & 1.98 & 2.20 & 2.00 & 0.693 & 0.506 \\
\hline $\begin{array}{l}\text { Restriction owing to } \\
\text { physical disabilities }\end{array}$ & 1.96 & 1.94 & 2.00 & 0.055 & 0.946 \\
\hline Body aches & 1.42 & 1.22 & 1.00 & 2.528 & 0.094 \\
\hline $\begin{array}{l}\text { Perception of general } \\
\text { health }\end{array}$ & 3.61 & 3.60 & 3.00 & 0.590 & 0.559 \\
\hline Vitality and energy & 3.38 & 3.61 & 3.00 & 1.715 & 0.194 \\
\hline Social functioning & 1.34 & 1.57 & 2.00 & 1.252 & 0.298 \\
\hline $\begin{array}{l}\text { Restriction owing to } \\
\text { emotional distress }\end{array}$ & 1.87 & 1.88 & 2.00 & 0.925 & 0.406 \\
\hline Mental health & 1.69 & 1.96 & 2.00 & 3.61 & 0.324 \\
\hline
\end{tabular}

SSS: Subjective social status, VVS: Vietnam social security, PDS: Public distribution system, ANOVA: Analysis of variance

TABLE 5. Assessing health according to marital status (Mann-Whitney $U$ test)

\begin{tabular}{lcccc}
\hline Scale & $\begin{array}{c}\text { Assessing the health of the } \\
\text { married respondents }\end{array}$ & $\begin{array}{c}\text { Assessing the health of the } \\
\text { unmarried respondents }\end{array}$ & Mann-Whitney U & $p$ \\
\hline Physical functioning & 22.06 & 17.90 & 148.50 & 0.274 \\
Restriction owing to physical & 20.38 & 20.70 & 184.50 & 0.854 \\
disabilities & 18.08 & & & \\
Body aches & 22.00 & 24.53 & 127.00 & 0.054 \\
Perception of general health & 23.08 & 18.00 & 150.00 & 0.281 \\
Vitality and energy & 20.28 & 16.20 & 123.00 & 0.065 \\
Social functioning & 20.30 & 20.87 & 182.00 & 0.870 \\
Restriction owing to emotional & & 20.83 & 182.50 & 0.866 \\
distress & 20.52 & 20.47 & 187.00 & 0.989 \\
Mental health & & & & \\
\hline
\end{tabular}


TABLE 6. Respondent satisfaction and quality of life (Mann-Whitney U test)

\begin{tabular}{lc}
\hline Scale & Pearson correlation \\
\hline Physical functioning & $0.180^{*}$ \\
Restriction owing to physical disabilities & $0.186^{*}$ \\
Body aches & $0.219^{*}$ \\
Perception of general health & $0.044^{* \star}$ \\
Vitality and energy & $0.199^{*}$ \\
Social functioning & $0.097^{\star *}$ \\
Restriction owing to emotional distress & $0.329^{*}$ \\
Mental health & $0.345^{*}$ \\
Total physical health & $0.250^{*}$ \\
Total mental health & $0.225^{\star}$ \\
\hline
\end{tabular}

that revealed a significant positive correlation between the above variables, we can confirm the working hypothesis: "Patient satisfaction 1 year after surgery: Rhinoplasty affected the quality of life."

\section{DISCUSSION}

Our study aimed to investigate the quality of life after surgery, considering the defined hypothesis and goals of empirical research. We evaluated the postoperative results of 40 patients after undergoing rhinoplasty, $50 \%$ of whom underwent rhinoplasty for purely esthetic reasons, whereas the other $50 \%$ underwent surgery for functional reasons. It is essential to emphasize that rhinoplasty almost always has an esthetic-functional component. Moreover, to make the sample as representative as possible, respondents of different ages, education levels, and marital status were surveyed. Regarding the representation of respondents in our sample in the context of educational attainment, most respondents had a university degree $(27,67.50 \%), 12$ respondents $(30 \%)$ were secondary school graduates, and only one $(2.5 \%)$ had completed postgraduate education. Regarding the marital status of the respondents in our sample, 25 were unmarried (62.50\%) and $15(37.50 \%)$ were married. Regarding the perceptions of general health, $90.00 \%$ of respondents stated that rhinoplasty had positively affected their general health, whereas $7.50 \%$ of respondents disagreed with this statement. Upon examining the possible differences in attitudes regarding the subjective health assessment among subjects who underwent rhinoplasty for functional reasons and those who underwent rhinoplasty for esthetic reasons, the results clearly showed no statistically significant differences $(p>0.05)$ based on the seven dimensions of health assessment. However, there was a significant difference related to physical pain ( $p=0.004<0.05$, Mann-Whitney U test). Upon testing the differences among respondents undergoing rhinoplasty for functional reasons and those undergoing rhinoplasty for esthetic reasons based on physical and mental health scales, no statistically significant value was observed in both groups related to the influence of these variables $(p=0.343$ $>0.05 ; p=0.946>0.05$ Mann-Whitney U test). Nevertheless, because to our knowledge, there is no similar research in our country and because it was a clinical sample $(N=40)$, the results obtained cannot be generalized to the population represented by this sample or to all women in Bosnia and Herzegovina who underwent nose surgery for functional or esthetic reasons. Hilhorst showed that women are objectively more willing to treat nasal deformities for functional and esthetic reasons, even if the procedures need to be performed over a longer time, even years. If they are confronted with a deformity of the nose after undergoing primary rhinoplasty, women will consent to a revision rhinoplasty procedure (with a theoretical statement of 9\%) within the next 5 years of life (8).

Since the nose is located in the center of the face, the shape of the nose is often regarded as an important determining element of overall facial esthetics. Therefore, rhinoplasty has become one of the most frequently performed facial surgeries. Facial symmetry is also recognized as a crucial factor in determining the attractiveness of the face. In our daily rhinoplasty practice, we frequently encounter patients with a deviated nose who are unaware of their underlying facial asymmetry (9). Plastic and cosmetic surgeons regularly report high satisfaction rates among their patients, and they have provided clinical and empirical evidence supporting positive outcomes in terms of patient satisfaction with cosmetic surgery procedures (1-4). Further, it has been assumed that a positive change in physical appearance for the patient will lead to an improvement in their psychological well-being, including their self-confidence and self-esteem (5-8). However, patient satisfaction with the procedures and changes 
in psychosocial status is two different, although related issues. Patients can be satisfied with the change in their appearance following the procedure but may experience no change in psychological characteristics (10). Based on the results presented, we can conclude that cosmetic surgery and satisfaction after surgery for esthetic and reconstructive surgery dramatically affect long-term mental health and happiness, similar to or even more than any other medical intervention.

\section{CONCLUSION}

The results indicated no significant difference in the subjective health assessment among the respondents who underwent rhinoplasty for functional reasons and those who underwent rhinoplasty for esthetic reasons, that is, the type of surgery did not affect the subjective health assessment of the respondents. On examining the relationship between the total physical and mental health and age of the respondents, no statistically significant values were recorded. There was no significant difference in health assessment in both groups of respondents related to their age. Moreover, it was proved that the respondents' age did not affect the degree of postoperative satisfaction. The results indicated no significant intergroup difference related to different educational levels based on all eight dimensions of health assessment. The data revealed that the level of education of the respondents did not correlate with the degree of postoperative satisfaction.

In addition, the results indicated no significant difference in the subjective health assessment between the married and unmarried respondents. The results indicated that marital status did not significantly affect the degree of postoperative satisfaction of respondents.

Finally, the satisfaction of respondents 1 year after the rhinoplasty affected their quality of life, which confirms the working hypothesis of the research.

\section{REFERENCES}

1. Milojevic B. Cosmetic and Plastic Surgery: How and Why? Zagreb: Milo Zagreb; 1991. p. 10-71.

2. Maletic DI. Cosmetic surgery. In: Practical Examples and Opportunities. Zagreb: Repro-Color; 2004. p. 14-52.

3. Yoo S, Most S. Nasal airway preservation using the autospreader technique: analysis of outcomes using a disease-specific quality-of-life instrument. Arch Facial Plast Surg 2011; 13(4):231-233

4. Guyuron B, Bokhari F. Patient satisfaction following rhinoplasty. Aesthetic Plast Surg 1996;20(2):153-157.

5. Dinis PB, Gomes A, Dinis M. Psychosocial consequences of nasal aesthetic and functional surgery: Prospective controlled study environment in ENT. Rhinol Port 1998;36:32-36.

6. Yildirim Y, Sertoz OO, Uyar M, Fadiloglu C, Uslu R. Hopelessness in Turkish cancer inpatients: The relation of hopelessness with psychological and disease-related outcomes. Eur J Oncol Nurs 2009;13(2):81-86. https://doi.org/10.1016/j.ejon.2009.01.001.

7. Rohrich RJ, Hollier LH. Use of spreader grafts in the external approach to rhinoplasty. Clin Plast Surg 1996;23(2):255. https://doi.org/10.1016/s0094-1298(20)31115-9.

8. Hilhorst MT. Philosophical pitfalls in cosmetic surgery: A case of rhinoplasty during adolescence. Med Hum 2002;28(2):61-65. https://doi.org/10.1136/mh.28.2.61.

9. Yi JS, Jang YJ. Frequency and characteristics of facial asymmetry in patients with deviated noses. JAMA Facial Plast Surg 2015;17(4):265-269. https://doi.org/10.1001/jamafacial.2015.0388.

10. Honigman RJ, Phillips KA, Castle DJ. A review of psychosocial outcomes for patients seeking cosmetic surgery. Plastic Reconstr Surg 2004;113(4):1229-1237.

https://doi.org/10.1097/01.prs.0000110214.88868.ca. 